\title{
Correction: Genetic Polymorphisms and Weight Loss in Obesity: A Randomised Trial of Hypo-Energetic High- versus Low-Fat Diets
}

Thorkild I. A. Sørensen, Philippe Boutin, Moira A. Taylor, Lesli H. Larsen, Camilla Verdich, Liselotte Petersen, Claus Holst, Søren M. Echwald, Christian Dina, Søren Toubro, Martin Petersen, Jan Polak, Karine Clément, J. Alfredo Martínez, Dominique Langin, Jean-Michel Oppert, Vladimir Stich, lan Macdonald, Peter Arner, Wim H. M Saris, Oluf Pedersen, Arne Astrup, Philippe Froguel, The NUGENOB Consortium

DOI: 10.1371/journal.pctr.0010012

In PLoS Clinical Trials, volume 1, issue 2:

The numbering of the reference citations in Table 2 is incorrect. The correct numbering is shown in the table below.

This correction note may be found online at DOI: 10.1371/journal.pctr.0010023.

Published August 25, 2006.

Citation: (2006) Correction: Genetic polymorphisms and weight loss in obesity: A randomised trial of hypo-energetic high- versus low-fat diets. PLoS Clin Trials 1(4): e23. DOI: 10.1371/journal.pctr.0010023 


\begin{tabular}{|c|c|c|c|c|c|c|c|c|c|c|c|}
\hline \multirow[t]{2}{*}{ Presumed Function of Genes } & \multirow[t]{2}{*}{ Normal Name } & \multirow[t]{2}{*}{ Gene Name } & \multirow[t]{2}{*}{ Locus ID } & \multirow[t]{2}{*}{ Location } & \multirow[t]{2}{*}{ Rs } & \multirow[t]{2}{*}{ SNP } & \multicolumn{3}{|c|}{ Genotype } & \multicolumn{2}{|c|}{$\begin{array}{l}\text { Hardy-Weinberg } \\
\text { Equilibrium }\end{array}$} \\
\hline & & & & & & & $\begin{array}{l}\text { Non- } \\
\text { carrier }\end{array}$ & $\begin{array}{l}\text { Hetero- } \\
\text { zygote }\end{array}$ & $\begin{array}{l}\text { Homo- } \\
\text { zygote }\end{array}$ & $\begin{array}{l}\text { Allele } \\
\text { Frequency }\end{array}$ & $p$-Value \\
\hline \multirow[t]{14}{*}{ Hypothalamic regulation of appetite } & $\begin{array}{l}\text { Solute carrier family } \\
6 \text { member } 14[15] \text { Women }^{\text {a }}\end{array}$ & SLC6A14 & 11254 & $\mathrm{Xq} 23$ & 2011162 & $+22510 C>G$ & 79 & 219 & 153 & 0.58 & 0.70 \\
\hline & $\begin{array}{l}\text { Solute carrier family } \\
6 \text { member } 14[15] \text { Men }^{\mathrm{a}}\end{array}$ & SLC6A14 & 11254 & $\mathrm{Xq} 23$ & 2011162 & $+22510 \mathrm{C}>\mathrm{G}$ & 66 & - & 80 & 0.55 & - \\
\hline & $\begin{array}{l}\text { Cocaine- and amphetamine- } \\
\text { regulated transcript [16] }\end{array}$ & CART & 9607 & $5 q 13.2$ & 7379701 & $-3608 \mathrm{~T}>\mathrm{C}^{2}$ & 150 & 305 & 170 & 0.52 & 0.58 \\
\hline & & & & & 6453132 & $-1702 C>T^{2}$ & 221 & 292 & 122 & 0.42 & 0.19 \\
\hline & & & & & & $-175 A>G^{2}$ & 155 & 303 & 163 & 0.51 & 1.00 \\
\hline & & & & & 5868607 & -1336 delA & 512 & 105 & 6 & 0.094 & 0.53 \\
\hline & $\begin{array}{l}\text { Growth hormone secreta- } \\
\text { gogue receptor }[17,18]\end{array}$ & GHSR & 2693 & $3 q 26.3$ & 2232169 & Leu149Leu & 599 & 25 & 0 & 0.022 & 1.00 \\
\hline & Glutamate decarboxylase 2 [19] & GAD2 & 2572 & 10p11.23 & 928197 & $+83897 \mathrm{~T}>\mathrm{A}$ & 426 & 169 & 31 & 0.18 & 0.0065 \\
\hline & & & & & 992990 & $+61450 \mathrm{C}>\mathrm{A}$ & 318 & 257 & 57 & 0.29 & 0.12 \\
\hline & & & & & 2236418 & $-243 A>G$ & 416 & 173 & 30 & 0.19 & 0.30 \\
\hline & Ghrelin $[20,21]$ & GHRL & 51738 & $3 p 25.3$ & 696217 & Leu72Met & 552 & 69 & 4 & 0.062 & 0.56 \\
\hline & $\begin{array}{l}\text { McKusick-Kaufman } \\
\text { syndrome [22] }\end{array}$ & MKKS & 8195 & $20 \mathrm{p} 12$ & 1547 & Arg517Cys & 505 & 120 & 1 & 0.097 & 0.57 \\
\hline & $\begin{array}{l}\text { Leptin receptor overlapping } \\
\text { transcript-like } 1[23]\end{array}$ & LEPROTL1 & 23484 & $8 p 21.2-1$ & & $-2625 C>T$ & 551 & 54 & 1 & 0.046 & 0.48 \\
\hline & $\begin{array}{l}\text { Proprotein convertase } \\
\text { subtilisin/kexin type } 1 \text { [24] }\end{array}$ & PCSK1 & 5122 & $5 q 15$ & 6235 & T690S C>G & 360 & 215 & 47 & 0.25 & 0.074 \\
\hline \multirow[t]{2}{*}{ Efficiency of energy expenditure } & Uncoupling protein 2 [25] & UCP2 & 7351 & $11 q 13$ & 6593669 & $-866 \mathrm{G}>\mathrm{A}$ & 250 & 307 & 81 & 0.37 & 0.50 \\
\hline & Uncoupling protein $3[26]$ & UCP3 & 7352 & $11 q 13$ & 1900849 & $-55 \mathrm{C}>\mathrm{T}$ & 351 & 239 & 46 & 0.26 & 0.94 \\
\hline \multirow{9}{*}{$\begin{array}{l}\text { Regulation of adipocyte differentiation } \\
\text { and function }\end{array}$} & Forkhead box C2 $[27,28]$ & FOXC2 & 2303 & $16 q 22-24$ & - & $-512 \mathrm{C}>\mathrm{T}$ & 86 & 288 & 227 & 0.62 & 0.31 \\
\hline & Peroxisome proliferative & PPARGC1A & 10891 & $4 p 15.1$ & 8192678 & Gly482Ser & 74 & 276 & 276 & 0.66 & 0.83 \\
\hline & $\begin{array}{l}\text { activated receptor. Gamma } \\
\text { coactivator 1. alpha }[29-31]\end{array}$ & & & & 2932963 & $+2962 \mathrm{~A}>\mathrm{G}$ & 178 & 298 & 151 & 0.48 & 0.73 \\
\hline & Peroxisome proliferative & PPARG2 & 5468 & $3 \mathrm{p} 25$ & 1801282 & Pro12Ala & 475 & 151 & 12 & 0.14 & 0.30 \\
\hline & activated receptor. Gamma & & & & 3856806 & $1431 \mathrm{C}>\mathrm{T}$ & 474 & 144 & 11 & 0.13 & 0.66 \\
\hline & isoform 2 [31-35] & & & & 7649970 & $-820 \mathrm{C}>\mathrm{T}$ & 465 & 147 & 13 & 0.14 & 0.64 \\
\hline & $\begin{array}{l}\text { Peroxisome proliferative } \\
\text { activated receptor. Gamma } \\
\text { isoform } 3 \text { [36] }\end{array}$ & PPARG3 & 5468 & $3 p 25$ & 10865710 & $-681 C>G$ & 346 & 258 & 37 & 0.26 & 0.57 \\
\hline & $\begin{array}{l}\text { Sterol regulatory element } \\
\text { binding transcription factor } 1 \text { [37] }\end{array}$ & SREBF1 & 6720 & $17 p 11.2$ & - & $17 C>G$ & 248 & 304 & 83 & 0.37 & 0.59 \\
\hline & $\begin{array}{l}\text { WW domain containing adaptor } \\
\text { with coiled-coil [38] }\end{array}$ & WAC & 51322 & 10p12.1 & 2807761 & $-829 A>G$ & 142 & 274 & 157 & 0.51 & 0.16 \\
\hline
\end{tabular}




\begin{tabular}{|c|c|c|c|c|c|c|c|c|c|c|c|}
\hline \multirow[t]{2}{*}{ Presumed Function of Genes } & \multirow[t]{2}{*}{ Normal Name } & \multirow[t]{2}{*}{ Gene Name } & \multirow[t]{2}{*}{ Locus ID } & \multirow[t]{2}{*}{ Location } & \multirow[t]{2}{*}{ Rs } & \multirow[t]{2}{*}{ SNP } & \multicolumn{3}{|c|}{ Genotype } & \multicolumn{2}{|c|}{$\begin{array}{l}\text { Hardy-Weinberg } \\
\text { Equilibrium }\end{array}$} \\
\hline & & & & & & & $\begin{array}{l}\text { Non- } \\
\text { carrier }\end{array}$ & $\begin{array}{l}\text { Hetero- } \\
\text { zygote }\end{array}$ & $\begin{array}{l}\text { Homo- } \\
\text { zygote }\end{array}$ & $\begin{array}{l}\text { Allele } \\
\text { Frequency }\end{array}$ & $p$-Value \\
\hline \multirow[t]{9}{*}{ Regulation of lipid and glucose metabolism } & $\begin{array}{l}\text { Hydroxysteroid (11-beta) } \\
\text { Dehydrogenase } 1[39-40]\end{array}$ & $H S D 11 B 1$ & 3290 & 1932.2 & 846919 & $-2940 \mathrm{G}>\mathrm{A}$ & 525 & 70 & 1 & 0.060 & 0.97 \\
\hline & Hepatic lipase C [41] & $\angle I P C$ & 3990 & $15 \mathrm{q} 21-23$ & 6082 & Asn215Ser & 280 & 282 & 71 & 0.33 & 0.91 \\
\hline & Insulin-like growth factor $2[42,43]$ & IGF2 & 3481 & $11 \mathrm{p} 15.5$ & 3168310 & $1926 C>G$ & 308 & 256 & $\begin{array}{l}21 \\
59\end{array}$ & $\begin{array}{l}0.22 \\
0.30\end{array}$ & 0.88 \\
\hline & & & & & & Apal $A>G$ & 320 & 257 & 55 & 0.29 & 0.99 \\
\hline & & & & & 3842759 & $-6815 \mathrm{~A}>\mathrm{T}$ & 325 & 251 & 55 & 0.29 & 0.78 \\
\hline & $\begin{array}{l}\text { Potassium inwardly rectifying } \\
\text { channel } J 11 \text { (KIR6.2) [44,45] }\end{array}$ & KCNJ11 & 3767 & $11 \mathrm{p} 15.1$ & 5219 & Glu23Lys & 241 & 300 & 73 & 0.36 & 0.26 \\
\hline & $\begin{array}{l}\text { Ectonucleotide pyrophosphatase/ } \\
\text { phosphodiesterase } 1[46]\end{array}$ & ENPP1 & 5167 & 6923.2 & - & IVS20delT-11 & 374 & 232 & 27 & 0.23 & 0.30 \\
\hline & & & & & 1044498 & Lys121GIn & 433 & 171 & 12 & 0.16 & 0.84 \\
\hline & & & & & 7754561 & $1044 \mathrm{~A}>\mathrm{G}$ & 318 & 244 & 40 & 0.27 & 0.34 \\
\hline \multirow{8}{*}{ Production of adipocytokines } & Adiponectin $[47,48]$ & $A D I P O Q$ & 9370 & 3927.3 & 266729 & $-11377 C>G$ & 356 & 236 & 38 & 0.25 & 0.32 \\
\hline & & & & & 2241766 & $+45 \mathrm{~T}>\mathrm{G}$ & 477 & 130 & 21 & 0.14 & 0.052 \\
\hline & & & & & 1501299 & $+276 \mathrm{~T}>\mathrm{G}$ & 76 & 233 & 323 & 0.70 & 0.021 \\
\hline & & & & & 17300539 & $-11391 \mathrm{G}>\mathrm{A}$ & 525 & 101 & 3 & 0.085 & 0.78 \\
\hline & CD36 antigen [49] & CD36 & 948 & $7 q 11.2$ & 2232169 & $-178 A>C$ & 110 & 294 & 189 & 0.57 & 0.68 \\
\hline & Interleukin $6[50,51]$ & IL6 & 3569 & $7 \mathrm{p} 21$ & 1800795 & $-174 \mathrm{G}>\mathrm{C}$ & 184 & 326 & 116 & 0.45 & 0.62 \\
\hline & Tumor necrosis factor alpha $[52,53]$ & $T N F \alpha$ & 7124 & $6 p 21.3$ & 1800629 & $-308 \mathrm{G}>\mathrm{A}$ & 459 & 159 & 14 & 0.15 & 0.011 \\
\hline & Serine proteinase inhibitor $1[54]$ & SERPINE1 & 5054 & $7 q 21.3-22$ & 1799889 & -67 insG & 157 & 259 & 140 & 0.49 & 0.099 \\
\hline \multicolumn{12}{|c|}{$\begin{array}{l}\text { The table is based on those obese individuals among the } 771 \text { enrolled in the NUGENOB study who completed the dietary intervention }(n=648) \text {, who have been genotyped }(n=643) \text { and who had a body mass index }<60 \text { ( } n=642) \text {. } \\
\text { The genes are grouped according to their known or presumed function leading to the association with the obesity-related phenotypes. } \\
\text { For SLCGA }\end{array}$} \\
\hline
\end{tabular}

